\title{
O vírus oropouche e o seu contexto epidemiológico na america latina no período de 2009 a 2019
}

\author{
The oropouche virus and epidemiological context in the amazon region from 2009 to 2019 \\ El virus de oropouche y su contexto epidemiológico en la amazonia en el período de 2009 \\ a 2019
}

Karla Fabiane Lopes de Melo ${ }^{1}$, Cláudio Renan de Souza Pereira ${ }^{2}$, Walter Felix Franco Neto ${ }^{3}$, Murilo Tavares Amorim ${ }^{4}$, Jardel Fábio Lopes Ferreira ${ }^{3}$, Ana Paula Sousa Araújo ${ }^{3}$, Francisco Canindé Ferreira de Luna ${ }^{1}$, Gustavo Moraes Holanda ${ }^{2}$, Samir Mansour Moraes Casseb ${ }^{3 *}$.

\section{RESUMO}

Objetivo: Descrever o vírus Oropouche e seu contexto epidemiológico na Amazônia entre os anos de 2009 a 2019. Métodos: Este trabalho é um estudo de uma revisão sistemática do tipo metassíntese qualitativa de perspectiva epidemiológica onde o levantamento de material foi realizado através de pesquisa em plataformas de busca online tendo como palavras-chaves como "Oropouche", "vírus Oropouche", "Oropouche Vírus" e "Oropouche and Amazon. Resultados: O vírus Oropouche (VORO) é um arbovírus que pertence à família Peribunyaviridae, gênero Orthobunyavirus. Seu primeiro isolado ocorreu em 1955, no Brasil o vírus foi primeiramente isolado em 1960 sendo até o momento a Amazônia o local mais afetado por este arbovírus. As principais características clínicas são febre, dor de cabeça e dores no corpo e por causa destes sintomas facilmente confundido com outros arbovírus como Dengue e Zika. Devido a falta de informação e sua semelhança clínica com outros arbovírus seu diagnóstico tanto clínico quanto laboratorial torna-se complexo. Considerações finais: Dado a situação atual do Vírus Oropouche no mundo, mas principalmente na América Latina, é possível observar que está ocorrendo uma expansão silenciosa deste vírus devido a dificuldade da pesquisa e identificação a cerca dos pacientes verdadeiramente positivos para este vírus.

Palavras-chave: Oropouche, Arbovírus, Epidemiologia.

\begin{abstract}
Objective: To describe the Oropouche virus and its epidemiological context in the Amazon between the years 2009 to 2019. Methods: This work is a study of a systematic review of the qualitative meta-synthesis type from an epidemiological perspective where the survey of the material was carried out through research on platforms search engine using keywords such as "Oropouche," "Oropouche virus," "Oropouche Virus and Amazon". Results: The Oropouche virus (VORO) is an arbovirus that belongs to the family Peribunyaviridae, genus Orthobunyavirus. Its first isolate occurred in 1955, in Brazil the virus was the first isolated in 1960 and the Amazon has so far been the site most affected by this arbovirus. The main clinical features are fever, headache, and body aches, and because of these symptoms easily confused with other arboviruses like Dengue and Zika. Due to the lack of information and its clinical similarity with other arboviruses, its diagnosis, both clinical and laboratory, becomes complex. Final considerations: Given the current situation of the Oropouche virus in the world, but mainly in Latin America, it is possible to observe that a silent expansion is taking the place of this virus due to the difficulty of research and identification of patients who are genuinely positive for this virus.
\end{abstract}

Keywords: Oropouche virus, Arboviruses, Epidemiology.

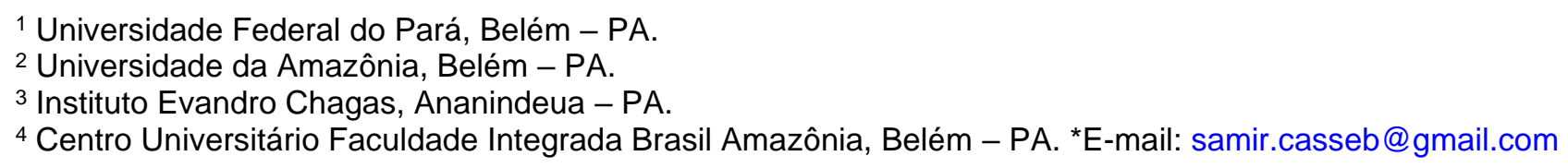




\section{RESUMEN}

Objetivo: Describir el virus Oropouche y su contexto epidemiológico en la Amazonía entre los años 2009 a 2019. Métodos: Este trabajo es un estudio de una revisión sistemática del tipo de meta-síntesis cualitativa desde una perspectiva epidemiológica donde la encuesta de material se realizó a través de la investigación en plataformas motor de búsqueda utilizando palabras clave como "Oropouche", "Oropouche virus", "Oropouche Virus" y "Oropouche and Amazon. Resultados: El virus Oropouche (VORO) es un arbovirus que pertenece a la familia Peribunyaviridae, género Orthobunyavirus. Su primer aislamiento ocurrió en 1955, en Brasil el virus se aisló por primera vez en 1960 y el Amazonas ha sido hasta ahora el sitio más afectado por este arbovirus. Las principales características clínicas son fiebre, dolor de cabeza y dolores corporales y, debido a estos síntomas, se confunden fácilmente con otros arbovirus como el dengue y el zika. Debido a la falta de información y su similitud clínica con otros arbovirus, su diagnóstico, tanto clínico como de laboratorio, se vuelve complejo. Consideraciones finales: Dada la situación actual del virus Oropouche en el mundo, pero principalmente en América Latina, es posible observar que se está produciendo una expansión silenciosa. de este virus debido a la dificultad de investigación e identificación de pacientes que son verdaderamente positivos para este virus.

Palabras clave: Virus Oropouche, Arboviroses, Epidemiología.

\section{INTRODUÇÃO}

Definem-se como arbovírus os vírus que possuem a capacidade de infectar biologicamente artrópodes e vertebrados como requisito essencial para o seu ciclo viral de manutenção. Os arbovírus que infectam os seres humanos estão nas seguintes famílias virais: Peribunyaviridae, Flaviviridae, Reoviridae, Rhabdoviridae e Togaviridae. Em sua maioria, os arbovírus apresentam o RNA como constituinte do seu genoma. Diferenciam-se quanto a número, segmentação e polaridade de seu genoma de RNA, que pode ser apresentado como uma ou duas fitas nucleotídicas, com ou sem segmentação e polaridade positiva, negativa ou ambisenso (BHAKAT S, et al., 2014).

As Doenças tropicais negligenciadas, como as arboviroses, estão entre as principais causas de mortalidade causadas por doenças infecciosas em países subdesenvolvidos ou em desenvolvimento. Vírus como: Vírus Dengue (VDEN), Vírus Chikungunya (VCHIK), Vírus Oropouche (VORO) e Vírus do Nilo Ocidental (VNO), têm causado surtos em diferentes regiões, apesar destes arbovírus serem considerados um sério problema de saúde pública, não existem medicamentos aprovados ou vacinas disponíveis para combater essas doenças (BHAKAT S, et al., 2014; GUBLER DJ, 2006).

Dentro deste contexto a região Amazônica tem sido objeto de inúmeros estudos e pesquisas que enfocam seu ambiente, sociedade e organismo. No que diz respeito à saúde, a Amazônia tem sido uma constante preocupação. Grandes impactos ambientais decorrentes das mudanças demográficas e sociais têm beneficiado a emergência ou reemergência de arboviroses. Desmatamentos, instalação de áreas urbanas em ambientes de florestas, aumento do turismo em áreas exóticas, entre outros, favorecem os mecanismos de migração dos vírus, auxiliando que estes deixem sua ecologia natural e passem a habitar novas localizações onde vetores artrópodes e hospedeiros suscetíveis forneçam condições para o surgimento de epidemias (GUBLER DJ, 2006).

O vírus Oropouche (VORO) pertence à família Peribunyaviridae, gênero Orthobunyavirus. Seu primeiro isolado ocorreu em 1955 a partir do sangue de um paciente febril e de um grupo de mosquitos Coquillettidia venezuelensis em Trindade e Tobago (THOMPSON R, et al., 2020). No Brasil o VORO foi isolado do sangue de um Bradypus tridactylus (preguiça) em 1960 (PINHEIRO D, 1962). Já foram identificados quatro genótipos do VORO em surtos no Panamá, Brasil, Peru e Trindade e Tobago (ROMERO-ALVAREZ D e ESCOBAR LE, 2017; MEDEIROS DBA e VASCONCELOS PFC, 2019).

No Brasil o vírus foi primeiramente isolado em 1960 no sangue de uma preguiça (Bradypus tridactylus) durante a construção da rodovia Belém-Brasília, no ano seguinte o vírus gerou uma grande epidemia de febre de Oropouche em Belém com cerca de 11.000 casos estimados e a partir da década de 80 o vírus se proliferou por outras áreas urbanas no norte do Brasil como: Acre, Amapá, Amazonas, Maranhão, Pará, Rondônia e 
Tocantins (Quadro 1), e em 1989 foi confirmado que vírus também se proliferava em outros países da América latina (Trindade e Tobago, Panamá e Peru) (LOPES N, et al., 2011; DA ROSA JFT, et al., 2017).

Quadro 1 - Áreas Brasileiras afetadas pelo Oropouche (entre 1961 e 2019).

\begin{tabular}{|l|l|}
\hline Estado & Municípios \\
\hline Pará & $\begin{array}{l}\text { Belém, Ananindeua, Benfica, Caratateua, Castanhal, Santa Isabel do Pará, Abaetetuba, } \\
\text { Baião, Bragança, Capanema, Curuçá, Tomé-Açu, Moju dos Campos, Vigia, Viseu, } \\
\text { Maracanã, Igarapé-Açu, Magalhães Barata, Belterra, Serra Pelada, Brasil Novo, } \\
\text { Itupiranga, Mojui dos Campos, Santarém, Marajó, Oriximiná, Altamira, Parauapebas, } \\
\text { Palhal, Curionópolis; Alter do Chão, Porto de Moz, Juruti e mesorregião do Baixo } \\
\text { Amazonas. }\end{array}$ \\
\hline Amazonas & Manaus, Novo Airão e Barcelos. \\
\hline Amapá & Mazagão e Cajari. \\
\hline Acre & Xapuri. \\
\hline Maranhão & Porto Franco. \\
\hline Rondônia & Ouro Preto D'Oeste e Ariquemes. \\
\hline Tocantins & Tocantinópolis. \\
\hline Mato Grosso & Cuiabá \\
\hline
\end{tabular}

Fonte: Melo KFL, et al., 2020. Adaptado de Da Rosa JFT, et al., 2017; Romero-Alvarez D e Escobar LE, 2017; Medeiros DBA e Vasconcelos PFC, 2019.

A transmissão de VORO ocorre por ciclos complexos do "tipo endêmico", ocorrendo em dois tipos de ciclos distintos: silvestre e urbano. O primeiro se inicia em um hospedeiro vertebrado primário, que podem ser preguiças (B. tridactylus), primatas não humanos e algumas aves (sendo um arbovírus com uma alta taxa de infecção em aves), todos estes atuam como hospedeiro do VORO na natureza, o vetor do vírus no ciclo silvestre é incerto, pois já foram isolados de mosquitos Ochlerotatus serratus, na Amazônia e de Coquilletidia venezuelensis em Trindade e Tobago.

O vetor então pica um Ser humano que, contaminado, vai para o meio urbano, iniciando o ciclo urbano, que tem como vetor o Culicoides paraenses e o Culex quinquefasciatus, durante o ciclo urbano o vírus é transmitido pela picada durante o repasto sanguíneo (GARCÍA MP, et al., 2016; VASCONCELOS HB, et al., 2009).

Todas as idades e ambos os sexos parecem ser igualmente susceptíveis à infecção. As características clínicas da febre de Oropouche incluem início abrupto de febre, calafrios, dor de cabeça severa, tonturas, mialgia, artralgia, náuseas e vômitos. Alguns pacientes podem apresentar um quadro de meningite asséptica (DA ROSA JFT, et al., 2017). A fase aguda da doença geralmente varia de dois a sete dias; no entanto, uma percentagem significativa de pessoas pode desenvolver uma recorrência dos sintomas dentro de 2-10 dias após se tornarem afebril, no entanto são usualmente menos severos.

Em 2012 o vírus foi recuperado do líquido cefalorraquidiano de 3 pacientes do Amazonas, isso sugere que durante surtos desse vírus no Brasil a doença pode estar comprometendo o sistema nervoso central (SNC) apesar da rota de invasão do SNC ser desconhecida (VASCONCELOS PFC, 2011; DA ROSA JFT, et al., 2017).

A perturbação na natureza vem sendo proposta como um dos principais agravantes para os surtos de Oropouche no Peru e no Brasil. No peru em áreas onde se teve perda significativa de vegetação (Madre de dios, Puerto Maldonado, lquitos, Lares, Pichari etc..) houve epidemias e as constantes mudanças climáticas e desflorestamento podem estar relacionados com a emergência não só da febre de Oropouche como de novos vírus (lquitos) (CRUZ ACR, et al., 2009).

No Brasil em 2016 segundo o ocorreu cerca de 1.500 .535 prováveis casos de Dengue, 215.319 casos prováveis de Zika e 271.824 casos prováveis de Chikungunya. A doença é constantemente confundida com VZIK, VDEN ou VCHIK fazendo o possível número real de casos estimados, chegar a mais de 500,000 
tornando o VORO, o segundo arbovírus mais frequente dos causadores de doença febril no Brasil (THOMPSON R, et al., 2020).

Desta maneira este trabalho tem como principal objetivo descrever o Vírus Oropouche e seu contexto epidemiológico na Amazônia entre os anos de 2009 a 2019. Além de demonstrar a expansão deste vírus na Amazônia durante o período deste estudo.

\section{MÉTODOS}

Este trabalho é um estudo de uma revisão sistemática do tipo metassíntese qualitativa de perspectiva epidemiológica o evantamento de material foi realizado através de pesquisa em plataformas de busca: Pubmed (Biblioteca Nacional de Medicina dos Estados Unidos), BVS (Biblioteca virtual de saúde), SCIELO (Scientific Electronic Library Online) e LILACS (base de dados Latino-Americana de informação bibliográfica em ciências da saúde).

O levantamento foi realizado no período de agosto de 2019 a novembro de 2019, almejando uma exploração de uma pesquisa explicativa no período de 2009 a 2018, em línguas inglesa e portuguesa. Para realizar esta busca foram utilizadas as seguintes descritores: Oropouche virus, Vírus Oropouche, Oropouche and Amazon, febre do oropouche e Oropouche fever.

Após esta buscas foi produzido um banco de dados em planilhas eletrônicas com cada uma das palavras chaves, sendo que em cada uma dessas planilhas foram inseridos os seguintes dados o Título da publicação, Ano da publicação, Autores, Língua do Texto, Meio de Publicação e o resumo.

Após este primeiro processamento foi realizado critérios de inclusão e exclusão para inserir os dados na análise final. Para os critérios de exclusão foi adotada uma leitura do resumo e todo o texto que não tinha uma descrição que relacionava vírus Oropouche e seu contexto epidemiológico, patológico e/ou causas de sua expansão sobre o território Amazônico foram descartados, textos que não estavam nos idiomas estabelecidos também foram excluídos, além de textos repetidos ou duplicados.

Os critérios de inclusão para o uso do material foram textos que descrevam a patogenia do Vírus Oropouche e suas características, que façam menção ao seu contexto epidemiológico e patológico; Trabalhos e artigos inéditos e originas, conclusivos, de livre acesso, nos idiomas português e inglês, e que foram publicados entre os anos de 2009 a 2019. Após esta leitura e do processo de inclusão e exclusão os textos restantes foram lidos de forma mais rigorosa e foram confrontados para desenvolver o texto final que está presente deste trabalho.

Além disto, utilizando-se de um sistema de informação geográfica (SIG), mais especificamente do software QGIS 2.18.20 da Open Source Geospatial Foundation (OSGeo) foi realizado um mapeamento da dispersão do vírus, desde sua descoberta em Trindade e Tobago em 1961 até os recentes casos no Peru e na Amazônia Brasileira, correlacionando à distribuição genotípica, época e possível área de dispersão.

\section{RESULTADOS E DISCUSSÃO}

O levantamento bibliográfico resultou em 662 artigos encontrados dentro do período estipulado, com isso após a aplicação dos critérios de inclusão e exclusão, 19 artigos estavam aptos a participar do estudo, dentre estes 8 em português e 11 em língua inglesa. Abaixo (Figura 1) segue os passos que foram seguidos para resultar neste número de artigos. 
Figura 1 - Descrição dos itens utilizados para a escolha dos artigos para a revisão sistemática.

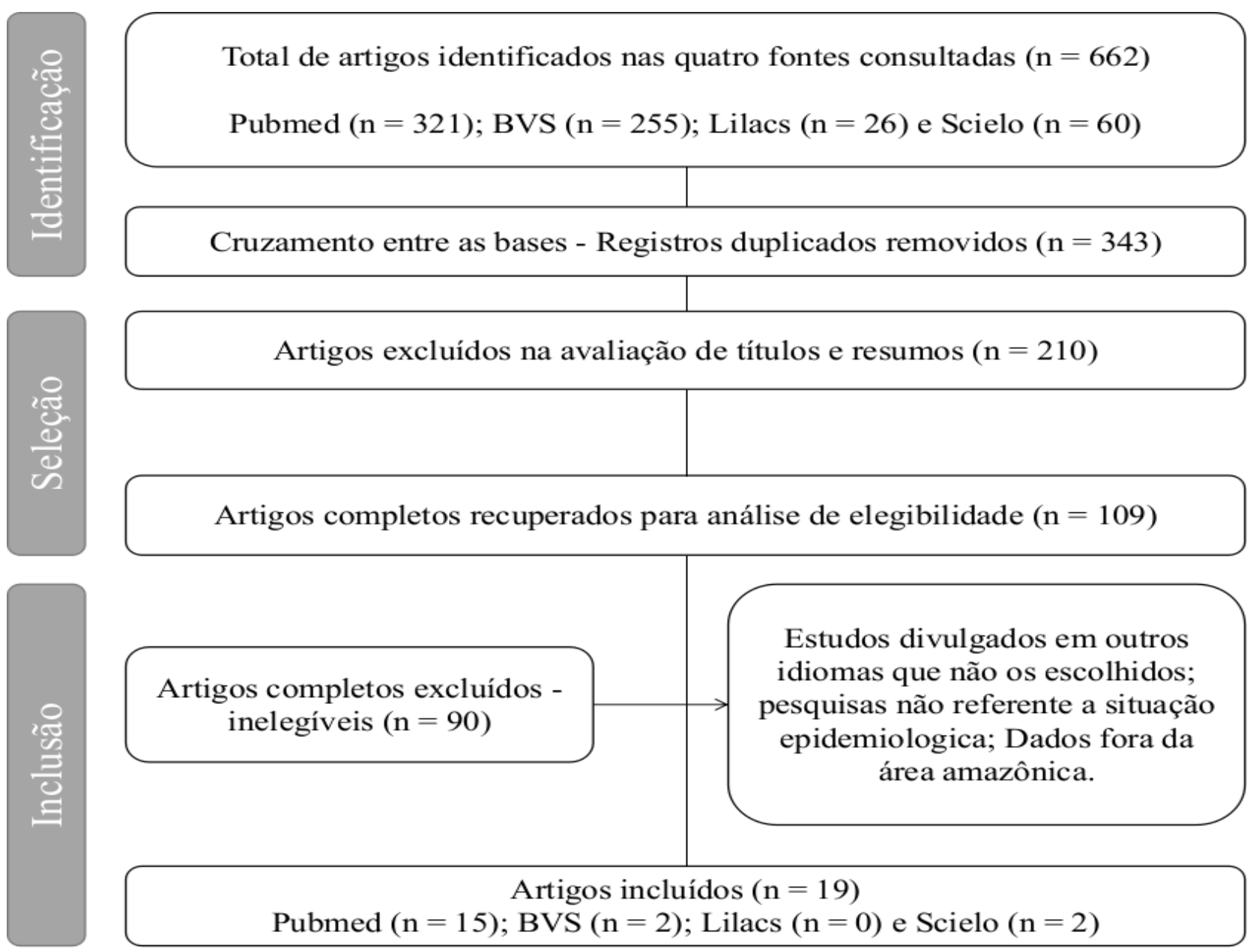

Fonte: Melo KFL, et al., 2020.

Os registros demonstram que o vírus Oropouche ocorre apenas na América latina, com o Peru, Brasil e Panamá (este último sem números oficiais de possíveis casos) são os únicos países afetados pela febre de Oropouche, mas Argentina, Bolívia, Colômbia, Equador e Venezuela já tiveram o isolamento do genoma viral em humanos ou animais selvagens (CRUZ ACR, et al., 2009). Segundo o levantamento Bibliográfico realizado neste trabalho entre os anos de 1961 até 2019 , no mundo a estimativa é que ocorreram cerca de 414,433 casos de febre de Oropouche, sendo que 413,465 são estimados apenas no Brasil, ou seja, 99,76\% dos casos estão na região Brasileira

Estudos sobre a biologia molecular do segmento pequeno do VORO sugeriram a existência de três genótipos I, II, III e IV (DA ROSA JFT et al., 2017). O genótipo III foi isolado de um hospedeiro vertebrado Callithrix sp. conhecido popularmente como Saguis no sudeste do Brasil, sugerindo possível dispersão do vírus para áreas suscetíveis e povoadas no Brasil (NUNES MRT, et al., 2009). Outras análises moleculares que utilizaram linhagens do VORO recuperadas durante surtos no Estado do Pará entre os anos de 2003 a 2007 demonstraram a circulação dos genótipos I e Il nesta região (GARCÍA MP, et al., 2016; VASCONCELOS HB, et al., 2009).

Primeiramente o VORO foi Notificado em Belém no ano de 1960, em 1967 vírus se dispersou para Bragança e continuou apenas no estado do Pará até o ano 1987, quando foi isolado no Município de Porto Franco no Maranhão, A partir de então o genótipo só foi notificado outra vez em 1996 em Xapuri no Acre e em outras regiões do Pará como: Oriximiná, Altamira e Parauapebas (Figura 2). Sendo que o primeiro genótipo emergiu a provavelmente à 112 anos atrás (VASCONCELOS PFC, 2011; DA ROSA JFT, et al., 2017). 
Figura 2 - Linha do Tempo dos Principais Pontos de Dispersão do Vírus Oropouche.

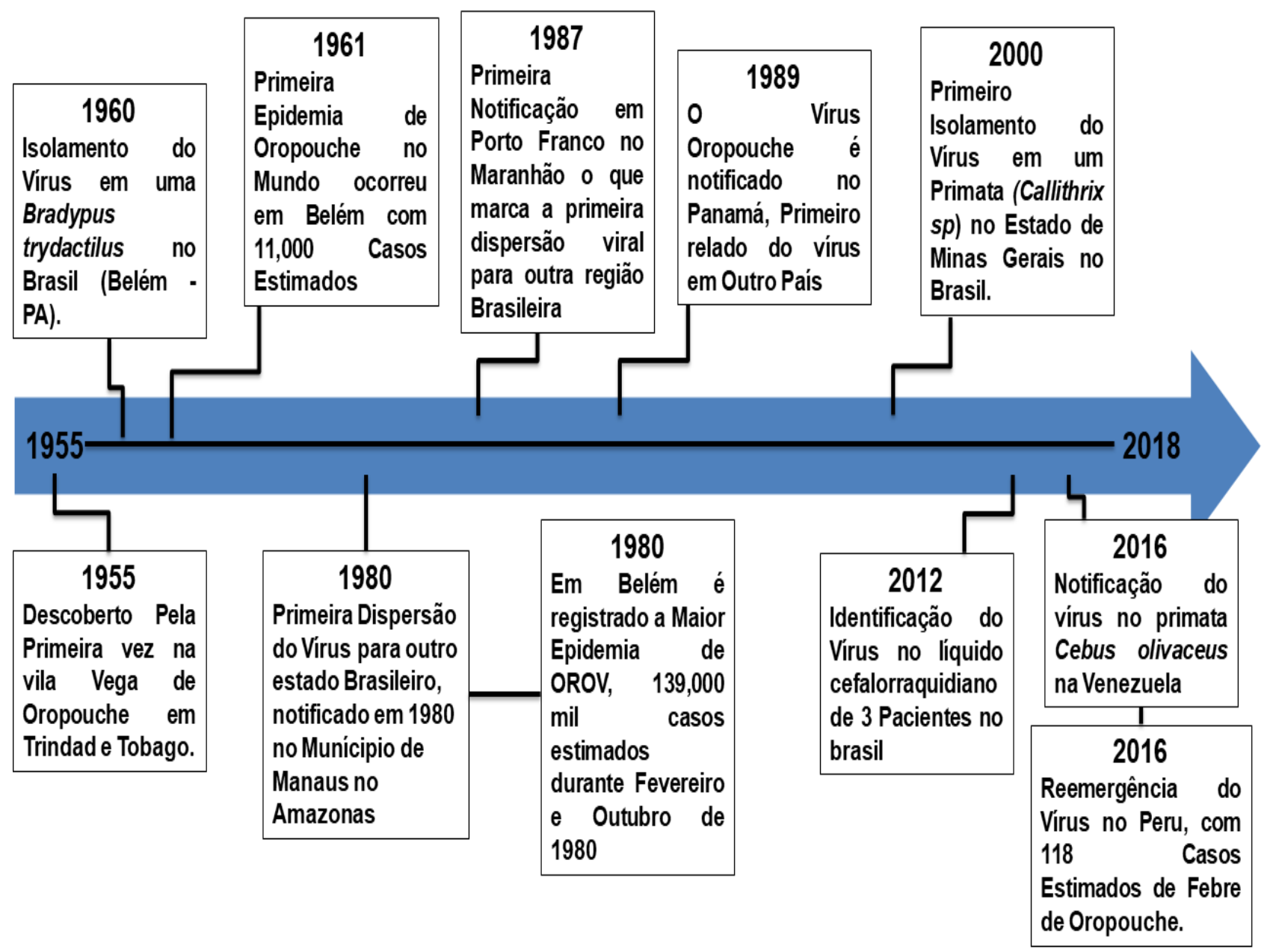

Fonte: Melo KFL, et al., 2020.

Aparentemente inicialmente o genótipo IV estava restrito apenas a região do Amazonas em Manaus. Sendo que este genótipo emergiu a provavelmente na década de 70 (VASCONCELOS PFC, 2011; DA ROSA JFT, et al., 2017). Se analisarmos o comportamento destes genótipos em relação a sua dispersão em todos estes anos, isto é, desde a descoberta do VORO até os dias atuais é possível criar um fluxo de origem e disseminação deste vírus (Figura 3).

Apesar do genótipo IV ter inicialmente ter seu aparecimento em Manaus (AM) este foi determinante para o avanço do oropouche por maiores áreas do território Amazônico e até mesmo fora da Amazônia. Antes da Introdução de Vírus Zika e VCHIK no território brasileiro, a febre Oropouche era considerada a segunda arbovirose com o maior número de notificações no país (VASCONCELOS PFC, 2011). A apresentação clínica clássica da febre Oropouche nos seres humanos inclui febre, mialgia, artralgia, dor de cabeça, fotofobia e erupção cutânea. Pacientes podem apresentar exantema morbiliforme, náuseas, diarreia, dor retro ocular e congestão conjuntival. Além disso, casos de hemorragias superficiais são comuns e podem ser acompanhadas por hemorragia gastrintestinal. Os sintomas podem durar de 2 a 7 dias, a recidiva clínica é observada em 56\% dos casos (PINHEIRO D, 1962; ROMERO-ALVAREZ D e ESCOBAR LE, 2017).

Em casos mais graves o paciente acometido pela febre Oropouche pode se tornar incapacitante, ficando limitado para realizar suas atividades de trabalho por até duas semanas, podendo levar até mesmo à internação hospitalar (CRUZ ACR, et al., 2009). 
Figura 3 - Rota de Dispersão de todos os Genótipos do vírus Oropouche, de 1955 aonde foi isolado pela primeira vez até 2019 onde se teve o último caso registrado no Peru.

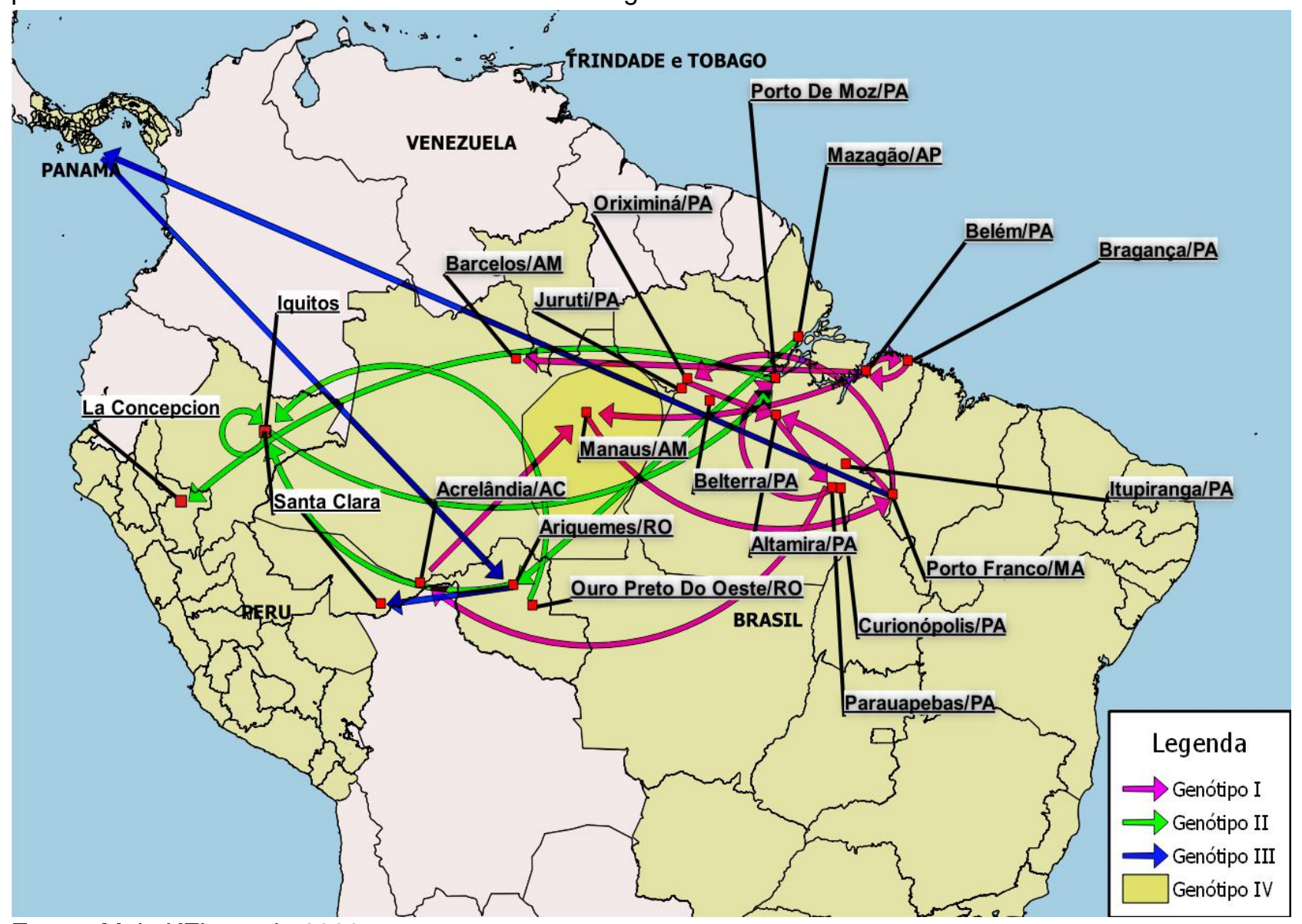

Fonte: Melo KFL, et al., 2020.

Amazônia brasileira possui cerca de $60 \%$ do total da extensão da floresta amazônica, desta área uma grande parte ainda é inexplorada e com a presença de animais nativos desta região. Estudo com animais selvagens foi possível detectar a presença do VORO nos organismos destes animais, aliado a este fato o baixo nível de imunização da população para este vírus em locais remotos, isto é, dentro da floresta amazônica acabam por colaborar com o surgimento dos surtos de VORO de forma esporádica. Estudo ao longo do tempo demonstram que principalmente em municípios considerados rurais ou com obras que demande um grau de impacto grande no meio ambiente (CRUZ ACR, et al., 2009; NUNES MRT, et al., 2009).

Além disso trabalhos relatam que a inserção de atividades agrícolas e de agropecuária em regiões antes de floresta, impactam de forma reversível estes locais. Pois faz com que as barreiras ecológicas, isto é, barreiras físicas que separam os possíveis vetores de arboviroses e áreas com população humana seja perdida de forma permanente (SILVA-CASO W, et al., 2019).

Estudos no Peru comprovaram esta hipótese ao observaram uma grande relação entre áreas recém devastadas com a expansão do vírus no país e também com a maior associação com graus de hemorragias diferentes, desta maneira se percebendo que o vírus oropouche acaba por ter sua expansão acelerada sempre que atividade rurais se expandiam sobre a floresta amazônica (SILVA-CASO W, et al., 2019; ALVAREZ-FALCONI PP e RIOS BAR 2010).

Em todo caso, a vigilância dos vetores para os arbovírus parece ser ainda uma das medidas mais eficazes para identificar e evitar possíveis surtos, sendo a Vigilância Entomológica uma ferramenta ainda interessante para este processo, mas importante para a Vigilância em Saúde. Além disso vegetações nativas como já relatado tornam-se uma boa estratégia para conter a expansão destes vetores e assim reduzindo o risco de expansão dos arbovírus (CARDOSO BF, et al., 2015). 
Um ponto importante também foi levantado por Valero N (2015) que acrescenta ainda a questão de que a grande variedade de doenças causadas por arbovírus deve ser algo a ser estudado tanto em conjunto quanto que individualmente, pois o rastreio de patógenos específicos pode facilitar o entendimento da ecologia e epidemiologia dos surtos, principalmente se as técnicas moleculares forem aplicadas para acrescentar dados quanto a origem dos vírus atuais, algo que Vasconcelos PFC (2011) e Gibrail MM, et al. (2016) enfatizou bem, ainda mais dado o grande número de reservatórios animais para o vírus Oropouche se abrigar, como dito por Batista PM, et al. (2013), algo que inclusive facilitaria a emergência e reemergência de arboviroses.

É importante ressaltar que apesar das dificuldades de "localizar o vírus" é possível descrever um grande número de indivíduos com anticorpos para o Oropouche o que pode indicar uma grande circulação deste vírus na área amazônica (BATISTA PM, et al., 2013).

Estudos moleculares demonstram a grande necessidade de entender melhor a clínica ocorrida em caso de infecção pelo vírus Oropouche, estima-se que grande parte dos casos não conclusivos para o VDEN, VZIK e VCHIK seja ocorrido por outro arbovírus. No entanto a dificuldade de caracterização dos sintomas para a possível diferenciação e de diagnósticos disponíveis para outros arbovírus como o Oropouche torna esta tarefa inviável e abre uma discussão sobre a possível expansão do vírus Oropouche sobre o território amazônico e brasileiro de forma silenciosa (GIBRAIL MM, et al., 2016).

Diante dessa situação, vários estudos como o de Batista PM, et al. (2013) acrescenta ainda que os programas de vigilância devem ser estimulados a manter uma monitorização dos animais silvestres e seres humanos doentes para que se possa entender se a transmissão seria unicamente humana ou se haveria influencia ambiente, onde neste último caso a intensa circulação de arbovírus nos próprios animais manteria os reservatórios das doenças para novos casos.

Casseb AR, et al. (2015) em seu estudo observou que o ambiente pode influenciar de forma positiva no desenvolvimento de novos surtos na América Latina da febre do Oropouche, pois a falta de vigilância em locais remotos acaba aumentando a fronteira de expansão do Oropouche.Colaborando com esses dados Romero-Alvarez D e Escobar LE (2017) também observam que o aumento da expansão deste vírus está intimamente ligada a falta de políticas públicas eficazes em locais onde o ambiente vem sendo transformado rapidamente, principalmente modificando de uma área selvagem para áreas Peri urbanas ou extremamente urbanizadas, mas sem infraestrutura, muito comum em áreas de extração vegetal ou de expansão agrícola.

A dificuldade de controle do fluxo de animais silvestres infectados entre populações de florestas vizinhas, bem como, a grande expansão agrícola e agropecuária pode implicar nos surtos esporádicos das doenças em regiões incomuns. Como em Mato Grosso, que apesar de estar fora da área amazônica (região endêmica), detectou-se a presença do segmento $S$ do vírus em pacientes febris (CARDOSO BF, et al., 2015). Além do mais o diagnóstico correto também é fator crucial para o entendimento da disseminação do vírus, visto que em situações como a que ocorrerá em Manaus (AM), onde muitos pacientes diagnosticados com Dengue, possuiriam na verdade o VORO, obscurece o real impacto do patógeno (MOURÃO MPG, et al., 2015; NAVECA FG, et al., 2018).

Outro ponto a ser avaliado, é de que regiões com incidência constantes de Dengue ou outras arboviroses pode representar um risco maior para disseminação do VORO (GARCIA MP, et al., 2016; VIANEZ JLSG, et al., 2016), dessa forma a inclusão da pesquisa e diagnóstico do VORO deve ser inserida nos planos de precaução para saúde e vigilância dos governos que possuem áreas na Amazônia visto podem tornar-se cada vez o maior problema de saúde no Brasil enfrentado por arboviroses emergentes como o Oropouche (ALVAURCIA C, et al., 2017; LADNER JT, et al., 2014).

As arboviroses pode várias vezes utilizarem os mesmos vetores para a sua expansão acabam por dificultar o entendimento das arboviroses de forma individual o que pode acarretar a uma dificuldade da vigilância e controle dessas doenças. É cada vez mais necessário uma melhor busca e aperfeiçoamento dos protocolos de diagnóstico clínicos e laboratoriais para as arboviroses, principalmente para as que ainda estão negligenciadas como o vírus Oropouche (NAVECA FG, et al., 2018; PURSE BV, et al., 2015). 


\section{CONSIDERAÇÕES FINAIS}

Dado a situação atual do VORO na América Latina, é possível observar que está ocorrendo uma expansão silenciosa deste agente infeccioso. Resultante da expansão de atividades agrícolas e de agropecuária, principalmente na região Amazônica. Infelizmente com este dados não são conclusivos em relação a detecção deste vírus em outras áreas do território brasileiro, assim não se pode garantir que o VORO não é um vírus circulante fora da região Amazônia e que possa estar causando surtos esporádicos em outros locais do Brasil e da América Latina.

\section{REFERÊNCIAS}

1. ALVA-URCIA C, et al. Emerging and reemerging arboviruses: A new threat in Eastern Peru. Roques P, editor. PLoS One. 2017; 12(11).

2. ALVAREZ-FALCONI PP, RíOS BAR. Oropuche fever outbreak in Bagazan, San Martin, Peru: epidemiological evaluation, gastrointestinal and hemorrhagic manifestations. Revista Gastroenterologia Peru. 2010; 30(4): 334-40.

3. BATISTA PM, et al. Detection of arboviruses of public health interest in free-living New World primates (Sapajus spp.; Alouatta caraya) captured in Mato Grosso do Sul, Brazil. Revista da Sociedade Brasileira de Medicina Tropical. 2013; 46(6): 684-90.

4. BATISTA PM, et al. Seroepidemiological monitoring in sentinel animals and vectors as part of arbovirus surveillance in the state of Mato Grosso do Sul, Brazil. Revista da Sociedade Brasileira de Medicina Tropical. 2012; 45(2):168-73.

5. BHAKAT S, et al. A perspective on targeting non-structural proteins to combat neglected tropical diseases: Dengue, West Nile and Chikungunya viruses. European Journal Medicinal Chemistry. 2014; 87: 677-702.

6. CARDOSO BF, et al. Detection of Oropouche virus segment $S$ in patients and in Culex quinquefasciatus in the state of Mato Grosso, Brazil. Memórias do Instituto Oswaldo Cruz. 2015; 110(6): 745-54.

7. CASSEB AR, et al. Prevalência de anticorpos contra arbovírus da família Bunyaviridae em búfalos de água. Ciência Animal Brasileira. 2015;16(3): 428-36.

8. CRUZ ACR, et al. Vigilância sorológica para arbovírus em Juruti, Pará, Brasil. Caderno de Saúde Publica. 2009; 25(11): 2517-23.

9. DA ROSA JFT, et al. Oropouche Virus: Clinical, Epidemiological, and Molecular Aspects of a Neglected Orthobunyavirus. The American Journal of Tropical Medicine and Hygiene. 2017; 96(5): 1019-30.

10. GARCÍA MP, et al. Detección de la circulación del virus Oropuche en la región Madre de Dios, Perú (diciembre 2015 - enero 2016). Revista Peruana de Medicina Experimental y Salud Publica. 2016; 33(2): 380.

11. GIBRAIL MM, et al. Detection of antibodies to Oropouche virus in non-human primates in Goiânia City, Goiás. Revista da Sociedade Brasileira de Medicina Tropical. 2016; 49(3): 357-60.

12. GUBLER DJ. Human Arbovirus Infections Worldwide. Ann N Y Acad Sci. 2006; 951(1): 13-24.

13. LADNER JT, et al. Genomic and phylogenetic characterization of viruses included in the Manzanilla and Oropouche species complexes of the genus Orthobunyavirus, family Bunyaviridae. Journal of General Virology. 2014; 95(5): $1055-66$.

14. LOPES N, et al. Características gerais e epidemiologia dos arbovírus emergentes no Brasil. Revista Pan-Amazônica de Saúde. 2011; 5: 55-64.

15. MEDEIROS DBA, VASCONCELOS PFC. Is the brazilian diverse environment is a crib for the emergence and maintenance of exotic arboviruses? An Academia Brasileira de Ciências. 2019; 91: 1-6.

16. MOURÃO MPG, et al. Arboviral diseases in the Western Brazilian Amazon: a perspective and analysis from a tertiary health \&amp; research center in Manaus, State of Amazonas. Revista da Sociedade Brasileira de Medicina Tropical. 2015; 48: 20-6.

17. NAVECA FG, et al. Human Orthobunyavirus Infections, Tefé, Amazonas, Brazil. PLoS Current. 2018.

18. NUNES MRT, et al. Eco-epidemiologia dos arbovírus na área de influência da rodovia Cuiabá-Santarém (BR 163), Estado do Pará, Brasil. Caderno de Saúde Publica. 2009; 25(12): 2583-602.

19. PINHEIRO D. Tetanus in the newborn. Revista Paulista de Medicina. 1962; 60:119-24.

20. PURSE BV, et al. Bionomics of Temperate and Tropical Culicoides Midges: Knowledge Gaps and Consequences for Transmission of Culicoides -Borne Viruses. Annual Review Entomology. 2015; 60(1): 373-92.

21. ROMERO-ALVAREZ D, ESCOBAR LE. Vegetation loss and the 2016 Oropouche fever outbreak in Peru. Memórias do Instituto Oswaldo Cruz. 2017; 112(4): 292-8.

22. SAKKAS H, et al. Oropouche Fever: A Review. Viruses. 2018; 10(4): 175.

23. SILVA-CASO W, et al. First outbreak of Oropouche Fever reported in a non-endemic western region of the Peruvian Amazon: Molecular diagnosis and clinical characteristics. International Journal of Infectious Diseases. 2019; 83: 13944.

24. THOMPSON R, et al. A Review of the Economic Evidence of Aedes -borne arboviruses and Aedes -borne Arboviral Disease Prevention and Control Strategies. Expert Review of Vaccines. 2020; 19: 143-162.

25. VALERO N. Oropouche Virus: what is it and how it is transmitted? Investigacion Clinica. 2017; 58(1): 1-2.

26. VASCONCELOS HB, et al. Oropouche fever epidemic in Northern Brazil: epidemiology and molecular characterization of isolates. Journal of Clinical Virology. 2009; 44(2): 129-33. 
27. VASCONCELOS PFC. Interview with Pedro Fernando da Costa Vasconcelos, MD, PhD. Vector-Borne and Zoonotic Diseases. 2011; 11(1): 93-7.

28. VIANEZ JLSG, et al. Isolation of Madre de Dios Virus (Orthobunyavirus; Bunyaviridae), an Oropouche Virus Species Reassortant, from a Monkey in Venezuela. The American Journal of Tropical Medicine and Hygiene. 2016; 95(2): 328-38. 